\title{
Vitamin D status and its relationship with age in type 2 diabetic patients
}

\author{
Leila Mahmodnia ${ }^{1}$, Mohamad Reza Tamadon², Maryam Sadoughi ${ }^{1}$, Sara Beigrezaei ${ }^{3 *}$
}

\begin{abstract}
Introduction: Type 2 diabetes has become a chronic worldwide epidemic with advancing complications and has caused many premature deaths. Its global prevalence is about 9.7\%, with 92.4 million suffering from the disease. Vitamin D level has been recently considered as an adjustable risk factor of cardiovascular diseases in individuals with type 2 diabetes.

Objectives: The aim of the current study is to investigate the frequency of vitamin D deficiency and the relationship between vitamin D serum levels and age in type 2 diabetes patients.

Patients and Methods: In this descriptive-analytic study, 101 type 2 diabetes patients of Imam Ali clinic in Shahrekord were investigated. Serum vitamin D levels of the participants were measured by DRG (USA) Elisa kits. The results were analyzed using SPSS software with a 95\% confidence level.

Results: Of 101 studied patients, 32 were male and 69 were female. The average age of the subjects was $61.25 \pm 11.75$ years. The average age of the males was $63.09 \pm 11.15$ years and the average age of the females was $60.39 \pm 12$ years. Around 72 subjects were vitamin D deficient. No significant difference of vitamin D levels between males and females $(P=0.985)$ was detected. Serum vitamin $\mathrm{D}$ levels of type 2 diabetes patients were significantly positive correlated with their ages $(r=0.282, P=0.004)$.

Conclusion: In the present study the prevalence of vitamin D deficiency in type 2 diabetes patients was $71.3 \%$. We found a positive significant relationship between the vitamin $\mathrm{D}$ level and age. It is possible that ageing process is not one of the causes of vitamin $\mathrm{D}$ deficiency.

Keywords: Vitamin D, Type 2 diabetes, Age

Please cite this paper as: Mahmodnia L, Tamadon MR, Sadoughi M, Beigrezaei S. Vitamin D status and its relationship with age in type 2 diabetic patients. J Parathyr Dis. 2017;5(2):45-48. DOI: 10.15171/jpd.2017.05.

Copyright ( 2017 The Author(s); Published by Nickan Research Institute. This is an open-access article distributed under the terms of the Creative Commons Attribution License, which permits unrestricted use, distribution, and reproduction in any medium, provided the original work is properly cited.
\end{abstract}

\section{Introduction}

Vitamin D deficiency, considered as a main popular health problem in the world, has developed into an epidemic in each country (1). Vitamin D deficiency has considerable effects on skeletal muscles and evidence shows that, those suffering from vitamin D inadequacy are at the risk of heart complications and death $(2,3)$. In the past decade, researchers have addressed that vitamin $\mathrm{D}$ plays a role in the pathogenesis of various chronic diseases like diabetes, hypertension, infections, autoimmune diseases, cancer and obesity (4). Various investigations detected that the expression of skeletal muscles vitamin D receptors significantly reduced with increasing age (5). Recent human studies have focused on the age-related changes in bones and metabolism during menopause, due to its deep impact on the equilibrium of minerals existed in bones, especially in those suffering from osteoporosis (4-6).

Type 2 diabetes has become a chronic worldwide epidemic with advancing complications and has caused many premature deaths. Its global prevalence is about $9.7 \%$, with 92.4 million suffering from the disease (7). Vitamin $\mathrm{D}$ level has been recently considered as an adjustable risk factor of cardiovascular diseases, in individuals with type 2 diabetes $(8,9)$. Changes in vitamin D3 and its circulating metabolites such as decrease in 1a-hydroxylase activity and increase in the activity of kidney 25 -hydroxylase have been demonstrated in animal and human studies in cases that suffering from type 2 diabetes (10). The correlation between low serum levels of vitamin $\mathrm{D}$ and decrease in insulin sensitivity has been reported in recent crosssectional investigations (11-13). Several epidemiological and cross-sectional investigations have detected that low levels of $25(\mathrm{OH}) \mathrm{D}$ in circulation are related to increase of fasting blood sugar, insulin and higher prevalence of diabetes $(14,15)$.

\section{Objectives}

The aim of this study is to consider the relationship of vitamin $\mathrm{D}$ levels and ages of type 2 diabetes individuals. Additionally we sought to consider the prevalence of 
Implication for health policy/practice/research/ medical education

Type 2 diabetes has become a chronic worldwide epidemic with advancing complications and has caused many premature deaths. Vitamin D level has been recently considered as an adjustable risk factor of cardiovascular diseases, in individuals with type 2 diabetes. Several epidemiological and cross-sectional investigations have detected that low levels of $25(\mathrm{OH}) \mathrm{D}$ in circulation are related to increase of fasting blood sugar, insulin and higher prevalence of diabetes and expression of skeletal muscles vitamin D receptors significantly reduced with increasing age.

vitamin $\mathrm{D}$ deficiency in type 2 diabetes patients.

Patients and Methods

In this descriptive-analytic study, 101 type 2 diabetes patients of Imam-Ali clinic in Shahrekord were included. The diagnostic criterion for diabetes was according to American Diabetes Association (ADA) (16). Diabetes patients who were undergoing dialysis or were receiving kidney transplant and mentally disabled patients that could not consciously agree to terms of the experiment were exempted from the study. Serum vitamin D levels of the participants were measured by DRG (USA) Elisa kits (17).

\section{Ethical issues}

The research adhered to the principles of the Declaration of Helsinki. The purpose and design of study were explained for all subjects and they completed an informed consent form. Ethical committee of Shahrekord University of Medical Science approved the protocol (\#IR.SKUMS. REC 1394.165).

\section{Statistical analysis}

To determine the association between the gender variable and vitamin D levels, the non-parametric Mann-Whitney $\mathrm{U}$ test was applied and to determine the relationship between vitamin D levels and sex Spearmen's correlation coefficient was used. The results obtained, upon being organized and corrected, were analyzed using SPSS (version 19.0, SPSS Inc., Chicago, Illinois, USA) software with a 95\% confidence level. In the current study, a patient is considered as suffering from vitamin $\mathrm{D}$ deficiency, if individual has a vitamin D serum level of less than 25 nmol/L. A $P$ value of below 0.05 was considered significant.

\section{Results}

Of 101 studied patients, 32 patients were male while 69 patients were female. The average age of the subjects was $61.25 \pm 11.75$ years, the average age of the males was $63.09 \pm 11.15$ years and the average age of the females was $60.39 \pm 12$ years. As shown in Table 1 , no significant difference was observed between the vitamin D levels and $\operatorname{sex}(P=0.985)$.

Of 101 diabetic patients, 72 individuals suffered vitamin $\mathrm{D}$ deficiency which is equivalent to $71.3 \%$ of these people.
Table 1. Serum levels of vitamin D in terms of gender

\begin{tabular}{lccc}
\hline Variable & Proportion & Vitamin D status (nmol/L) & $P$ value \\
\hline Gender & & & 0.985 \\
Men & 32 & $18.13 \pm 2.45$ & \\
Women & 69 & $17.85 \pm 1.48$ & \\
Total & 101 & $17.97 \pm 1.24$ & \\
\hline
\end{tabular}

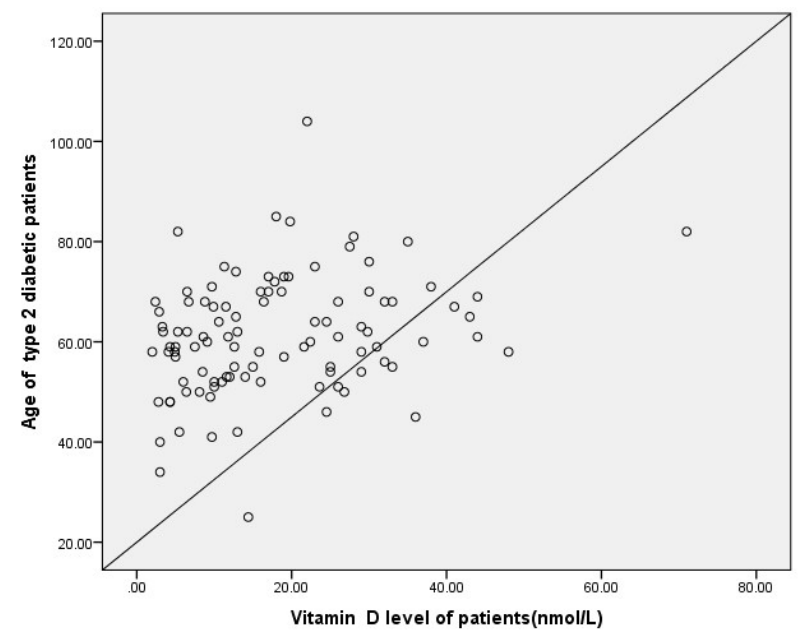

Figure 1. Serum vitamin $D$ levels of type 2 diabetes patients were significantly correlated with their ages $(r=0.282, P=0.004)$.

The average serum levels of vitamin $\mathrm{D}$ in patients were $17.94 \pm 12.16 \mathrm{nmol} / \mathrm{L}$. We found that serum vitamin D levels of type 2 diabetes patients were significantly correlated with their ages $(r=0.282, P=0.004$; Figure 1$)$. Vitamin D levels in diabetic men and women had no significant difference $(P>0.5)$.

\section{Discussion}

In the present study the prevalence of vitamin $\mathrm{D}$ deficiency in type 2 diabetes patients have been $71.3 \%$. Furthermore, vitamin $\mathrm{D}$ levels in diabetic men and women had no significant difference $(P>0.5)$. We found a positive significant relationship between the vitamin $\mathrm{D}$ level and age.

In the study conducted by Sadiya et al, on type 2 diabetes patients and obese individuals, $83.2 \%$ of individuals were vitamin $\mathrm{D}$ deficient and only $4.5 \%$ of them had normal levels of vitamin D (18). In their study the prevalence of vitamin $\mathrm{D}$ deficiency was higher among women. By contrast, in current study no significant difference of vitamin $\mathrm{D}$ between females and the males was detected. The results of their study showed a positive relationship between serum 25(OH) D serum level and age of diabetes patients, a finding that was observed in our study too. Accordingly, the study by Kafshani et al detected no positive significant relationship between serum vitamin $\mathrm{D}$ values of diabetes patients with their age and gender. However, in the present study we found a significant relationship between healthy individuals' ages and their vitamin D levels (19). In other studies carried out in the Middle East, the positive relationship between the 
participants' vitamin D levels and their ages was observed too $(20,21)$. A recent study by Alfawaz et al, in Saudi Arabia, referred to a positive relationship of serum vitamin $\mathrm{D}$ levels of the individuals, with their age (21). Previously in the study of Iranian healthy adults, by Baradaran et al, no significant correlation of gender and their vitamin D levels was detected. However, a positive correlation of age serum vitamin D levels was seen (22). In another study on diabetes patients in China, vitamin D levels of women were lower than those of men (23). Moreover, in the study by Sherman et al, as in our study, no difference between the level of $25(\mathrm{OH}) \mathrm{D}$ in circulation in men and women was seen (24).

Vitamin $\mathrm{D}$ and its metabolites have important impact on insulin biosynthesis and its secretion. Additionally, vitamin $\mathrm{D}$ had a significant influence on subsiding of inflammatory process in type 2 diabetes (25). As recent investigations have detected, a severe deficiency of vitamin D suppresses pancreas secretion and insulin circulation which leads to low insulin levels and glucose toleration disorder $(26,27)$. As in the current studies, low vitamin D serum values are associated independently to abdominal obesity and hyperglycemia (28). There also has been shown that the skeletal muscle tissue contains vitamin D receptors and to reach its highest functionality, muscles require an adequate vitamin D status (29).

Furthermore, it has been observed that vitamin D receptors presented in skeletal muscles and decreased with aging process $(5,30)$.

\section{Conclusion}

In the present study the prevalence of vitamin D deficiency in type 2 diabetes patients was $71.3 \%$. We found a positive significant relationship between the vitamin $\mathrm{D}$ level and age. It is possible that ageing process is not one of the causes of vitamin $\mathrm{D}$ deficiency. This finding requires to re-check in larger and multi-centric investigations.

\section{Limitations of the study}

Low proportion of patients is a limitation of our study. We suggest larger investigation on this aspect of diabetic disease.

\section{Authors' contribution}

All authors participated to design of the study. LM managed the research. MS performed the investigation. SBR analyzed the data. MRT and SBR prepared the manuscript. All authors read, revised and approved the manuscript.

\section{Conflicts of interest}

The authors declare that they have no competing interests.

\section{Ethical considerations}

Ethical issues (including plagiarism, data fabrication, double publication) have been completely observed by the authors.

\section{Funding/ Support}

This study was extracted from MD thesis of Maryam Sadoughi (\# 1252) and supported by the Vice-Chancellery for Research and Technology of Shahrekord University of Medical Sciences.

\section{References}

1. Hilger J, Friedel A, Herr R, Rausch T, Roos F, Wahl DA, et al. A systematic review of vitamin D status in populations worldwide. Br J Nutr. 2014;111:23-45.

2. Munger KL, Levin LI, Hollis BW, Howard NS, Ascherio A. Serum 25-hydroxyvitamin D levels and risk of multiple sclerosis. J Am Med Assoc. 2006;296:2832-8.

3. Wang TJ, Pencina MJ, Booth SL, Jacques PF, Ingelsson E, Lanier $\mathrm{K}$, et al. Vitamin D deficiency and risk of cardiovascular disease. Circulation. 2008;117:503-11.

4. Rawal G, Yadav S, Shokeen P. Health and the vitamin D. Int J Health Sci Res. 2015;5:416-23.

5. Simpson R, Thomas G, Arnold A. Identification of 1, 25-dihydroxyvitamin D3 receptors and activities in muscle. J Biol Chem.1985;260:8882-91.

6. Riggs BL, Melton III LJ. The prevention and treatment of osteoporosis. N Engl J Med. 1992;327:620-7.

7. Yang W, Lu J, Weng J, Jia W, Ji L, Xiao J, et al. Prevalence of diabetes among men and women in China. N Engl J Med. 2010;362:1090-101.

8. Dalgård C, Petersen MS, Weihe P, Grandjean P. Vitamin D status in relation to glucose metabolism and type 2 diabetes in septuagenarians. Diabetes Care. 2011;346:1284-8.

9. Bierschenk L, Alexander J, Wasserfall C, Haller M, Schatz D, Atkinson M. Vitamin D levels in subjects with and without type 1 diabetes residing in a solar rich environment. Diabetes Care. 2009;321:1977-9.

10. Isaia $G$, Giorgino $R$, Adami $S$. High prevalence of hypovitaminosis $\mathrm{D}$ in female type 2 diabetic population. Diabetes Care. 2001;24:1496.

11. Scragg R, Sowers M, Bell C. Serum 25-hydroxyvitamin D, diabetes, and ethnicity in the Third National Health and Nutrition Examination Survey. Diabetes care. 2004;27:28138.

12. Orwoll E, Riddle M, Prince M. Effects of vitamin D on insulin and glucagon secretion in non-insulin-dependent diabetes mellitus. Am J Clin Nutr. 1994;59:1083.

13. Borissova A, Tankova T, Kirilov G, Dakovska L, Kovacheva $\mathrm{R}$. The effect of vitamin D3 on insulin secretion and peripheral insulin sensitivity in type 2 diabetic patients. Int J Clin Pract Suppl. 2003;57:258-61.

14. Binkley $\mathrm{N}$, Ramamurthy $\mathrm{R}$, Krueger D. Low vitamin D status: definition, prevalence, consequences, and correction. Rheum Dis Clin North Am. 2012;38:45-59.

15. Muscogiuri G, Sorice G, Ajjan R, Mezza T, Pilz S, Prioletta $\mathrm{A}$, et al. Can vitamin $\mathrm{D}$ deficiency cause diabetes and cardiovascular diseases? Present evidence and future perspectives. Nutr Metab Cardiovasc Dis. 2012;22:81-7.

16. Association AD. Diagnosis and classification of diabetes mellitus. Diabetes care. 2006;29:S43.

17. Liu J-J, Wong MD, Toy WC, Tan CS, Liu S, Ng XW, et al. Lower circulating irisin is associated with type 2 diabetes mellitus. J Diabetes Complications. 2013;27:365-9.

18. Sadiya A, Ahmed SM, Skaria S, Abusnana S. Vitamin $\mathrm{D}$ status and its relationship with metabolic markers in persons with obesity and type 2 diabetes in the UAE: a cross-sectional study. Diabetes Res. 2014;2014:869307. 
19. Kafeshani M, Zarafshani M, Shokri-Moghaddam S, Ahmadi A, Nasri H. Serum 25-hydroxy vitamin D level in diabetic patients versus normal individuals; a pilot study. J Parathyr Dis. 2016;42:41.

20. Abiaka C, Delghandi M, Kaur M, Al-Saleh M. Vitamin D status and anthropometric indices of an Omani study population. Sultan Qaboos Univ Med J. 2013;13:224.

21. Alfawaz H, Tamim H, Alharbi S, Aljaser S, Tamimi W. Vitamin D status among patients visiting a tertiary care center in Riyadh, Saudi Arabia: a retrospective review of 3475 cases. BMC Public Health. 2014;14:159.

22. Baradaran A, Behradmanesh S, Nasri H. Association of body mass index and serum vitamin $\mathrm{D}$ level in healthy Iranian adolescents. Endokrynol Pol. 2012;63:29-33.

23. Kim YJ, Park SO, Kim TH, Lee JH, Kim SH. The association of serum 25-hydroxyvitamin D and vertebral fractures in patients with type 2 diabetes. Endocr J. 2013;60:179-84.

24. Sherman SS, Hollis BW, Tobin JD. Vitamin D Status and Related Parameters in a Healthy Population: The Effects of Age, Sex, and Season. J Clin Endocrinol Metab. 1990;71:405-13.

25. Savkur RS, Bramlett KS, Stayrook KR, Nagpal S, Burris
TP. Coactivation of the human vitamin $\mathrm{D}$ receptor by the peroxisome proliferator-activated receptor $\gamma$ coactivator-1 a. Mol Pharmacol. 2005;68:511-7.

26. Bourlon P, Billaudel B, Faure-Dussert A. Influence of vitamin D3 deficiency and 1, 25 dihydroxyvitamin D3 on de novo insulin biosynthesis in the islets of the rat endocrine pancreas. J Endocrinol. 1999;160:87-95.

27. Norman AW, Frankel J, Heldt AM, Grodsky GM. Vitamin D deficiency inhibits pancreatic secretion of insulin. Science. 1980;209:823-5.

28. Nimitphong H, Chanprasertyothin S, Jongjaroenprasert W, Ongphiphadhanakul B. The association between vitamin D status and circulating adiponectin independent of adiposity in subjects with abnormal glucose tolerance. Endocrine. 2009;36:205-10.

29. Rasheed K, Sethi P, Bixby E. Severe vitamin D deficiency induced myopathy associated with rhabydomyolysis. Am J Med Sci. 2013;55:334.

30. Bischoff-Ferrari H, Borchers M, Gudat F, Dürmüller U, Stähelin H, Dick W. Vitamin D receptor expression in human muscle tissue decreases with age. J Bone Miner Res. 2004;19:265-9. 